\title{
Avoiding the Avoidable: Towards a European Heat Waves Risk Governance
}

\author{
Wiebke Lass*, Armin Haas, Jochen Hinkel, and Carlo Jaeger \\ Potsdam Institute for Climate Impact Research (PIK), D-14412 Potsdam, Germany
}

\begin{abstract}
The death toll of recent heat waves in developed countries has been remarkably high, contradicting the common assumption that high levels of economic and technological development automatically lead to lower vulnerability to weather extremes. Future climate change may further increase this vulnerability. In this article we examine some recent evidence of heat wave-related mortality and we conclude that while economic wealth and technological capacity might be a necessary condition for adequately coping with adverse climate change effects, they are not sufficient. Questions of awareness, preparedness, organizational issues, and actor networks have to be addressed in a proactive and focused manner in order to avoid future heat wave damages. We propose some practical consequences for heat wave adaptation measures by adopting a risk governance framework that can be universally applied, as it is sufficiently flexible to deal with the multi-level and often fragmented reality of existing coping measures.
\end{abstract}

Keywords climate change adaptation, early warning systems, heat waves, risk governance, risk management

\section{Introduction}

Climate change is already underway and will continue in the future. Measurements show that Global Mean Temperature (GMT) has already increased by $0.76^{\circ} \mathrm{C}$ compared to pre-industrial levels, and the climate system is committed to an additional increase of $0.6^{\circ} \mathrm{C}$ due to historic emissions (IPCC 2007). Given the recent growth in global greenhouse gas (GHG) emissions (GCP 2010), this temperature increase will only be the lower boundary of what the future will bring.

While national and international climate policies that aim to reduce global GHG emissions are essential in order to prevent climate change and related impacts from becoming disastrous, human societies will have to adapt to changing climatic conditions.

Climate change has many different adverse impacts, with melting ice caps and rising sea levels being most probably

\footnotetext{
* Corresponding author. E-mail: wiebke.lass@pik-potsdam.de
}

the most severe ones in the very long run. In the short run, weather-related disasters such as droughts, floods, and storms play an important role. Worldwide, the number of disaster losses in monetary terms (both insured and uninsured) has increased in recent years but it is still debated whether (and, if yes, to what extend) climate change has contributed to this increase (Bouwer 2011). However, climate science warns us that increasing mean values - such as GMT-come with an increased risk of weather extremes in the future: "In a warmer future climate, there will be an increased risk of more intense, more frequent and longer-lasting heat waves. The European heat wave of 2003 is an example of the type of extreme heat event lasting from several days to over a week that is likely to become more common in a warmer future climate." (IPCC 2007, 783).

This article focuses on hot spells and heat waves as pertinent disasters, and as events with a risk of higher frequencies and intensities due to climate change. Various heat wave events in the recent past, which led to numerous deaths, have raised the attention of both scientists and decision makers across the globe. Here, we examine this issue from an integrated risk governance perspective. We focus on Europe, although heat waves do frequently occur in other continents where many countries often are perceived to have much lower coping capacities. This is exactly why we find Europe a very interesting case. Usually, developing countries are perceived as being both most exposed and most vulnerable to climate change, while developed countries - despite their responsibility in terms of high actual and historic emissionsseem to be neither especially exposed nor particularly vulnerable due to their technological, organizational, and financial capacities to cope with adverse effects of climate change. In particular the heat wave events of 2003 and 2010 in Europe lead us to correct these underlying assumptions. It seems that even the most advanced countries need to rethink their existing risk governance structures.

Against this background, this article develops an integrated risk governance framework for heat waves in Europe, based upon European experiences with recent heat waves as well as with existing coping strategies. The rest of this article is organized as follows: After a characterization of heat waves, their recent occurrence, and their future developments 
(section 2), we look at existing coping strategies (especially early warning systems) in Europe (section 3). Based on this background, we then present a risk governance perspective and apply it to heat waves (section 4). The final section draws some conclusions and links the heat wave case to the wider picture of climate policy.

\section{Heat Waves in Europe: Characteristics, Recent Events, and Future Trends}

Heat, or anomalously hot weather, that lasts for several days, often codified as heat waves, has a clear impact on societies including a rise in mortality and morbidity. Heat waves also place an increased strain on infrastructure (power, water, and transport), with monetary damages rising continuously. This text focuses on the impacts on human health, namely mortality. One would expect European societies to be rather well prepared when it comes to climate change adaptation, but the evidence presented in this article raises some doubt about this assumption.

\subsection{Characteristics}

A heat wave is a prolonged period of excessively hot weather, which may be accompanied by high humidity. There is no universal definition of a heat wave (Souch and Grimmond 2006; Robinson 2001). The term is relative to the usual weather in the area. Temperatures that people from a hotter climate consider normal can be termed a heat wave in a cooler area if they are outside the normal climate pattern for that area. The definition recommended by the World Meteorological Organization is when the daily maximum temperature of more than five consecutive days exceeds the average maximum temperature by 5 Celsius degrees (9 Fahrenheit degrees), the normal period being 1961-1990 (Frich et al. 2002).

Increased summer heat does have various critical effects for natural, semi-natural, technical, and social systems $\mathrm{s}^{\mathrm{i}}$ :

- Natural systems may come under heat and water stress, leading to losses of functions and a reduction of ecosystem service deliveries (such as water purification). Some wild living animals are more susceptible to infectious diseases under heat stress conditions (Seppälä and Jokela 2011). Despite certainly very important attempts to monetize ecosystem goods and services (Costanza et al. 1997; Millennium Ecosystem Assessment 2005), it is hard to quantify damages due to external shocks. This makes risk management strategies difficult - even if we leave aside the question of whether human intervention in largely unmanaged ecosystems can at all reduce risks.

- Semi-natural systems can experience the same or even larger stress effects, such as forest fires or crop losses.i This makes quantitative and monetized damage estimates much easier, and we find systems of risk management (including disaster induced crop loss insurances) already in place.

- Technical systems are vulnerable towards heat stress, and many of them are technically protected against it (for instance, cooling systems for buildings, trucks, or computers). Usually, technical systems have standard ranges of "normal" functioning, beyond of which the risk of malfunction increases. Transport infrastructures such as streets or railways are repeatedly damaged during heat stress periods.

- Social actors and systems are equally "tuned" towards normal ranges of weather patterns, including frequently occurring weather extremes. Beyond these limits, which vary from system to system and from actor to actor, they become vulnerable to damages (McMichael, Woodruff, and Hales 2006).

Heat waves do carry sustained heat loads to the human body and have discernible impacts on human health (Kovats and Jendritzky 2006; Dhainaut et al. 2004). They affect well-being and limit the normal functioning of humans, and can stress the cardiovascular system.

Unlike air pollution the effects of temperature on mortality cannot be assumed to follow a general linear form. In populations with a temperate climate, a general U- or V-shaped relationship exists between daily mortality counts and temperature, with deaths increasing as temperatures fall, as well as when temperatures rise above population-specific threshold values (Curriero et al. 2002; Hajat et al. 2010; Kovats and Hajat 2008). These stress-mortality curves vary from region to region. Despite this variance, a couple of risk factors increase heat wave damage probabilities:

- Factors affecting exposure (such as working outside or residing in a retirement home without air-conditioning);

- Factors affecting sensitivity to a given heat exposure (such as age, sex, health condition, or body mass); and

- Factors affecting access to treatment (such as lack of information or medication).

Empirical studies reveal that infants and elderly people (especially $75+$ ) are particularly vulnerable to heat wavesmostly due to all three factors mentioned (Conti 2011; Koppe 2005; Kovats and Hajat 2008; Simón et al. 2005; Schifano et al. 2009). Vulnerability to heat wave is significantly increased due to pre-existing respiratory and cardiovascular diseases (D'Ippoliti et al. 2010; Patz et al. 2005). There is a significant social component of vulnerability. This component is an important factor for explaining some variance in mortality between different European cities during the 2003 heat wave (D'Ippoliti et al. 2010). Another empirical evidence is that women tend to be more at risk than men, although the evidence here is less clear. While U.S. studies show that low socioeconomic status is associated with higher mortality risks, data for Europe do not reveal this connection (with some exceptions: Michelozzi et al. 2005), most probably due to the better provisioning of social services in Europe. 
People living in urban environments are at greater risk than those in non-urban regions. Recent studies for European cities revealed that heat waves of long duration had the greatest impact on mortality, and resulted in 1.5 to 3 times higher daily mortality than other periods (D'Ippoliti et al. 2010). Worldwide we live in an increasingly urbanized society, urban heat island effects underline and reinforce the relevance of heat waves for the risk management of modern societies. Thermally inefficient housing and the so-called urban heat island effect (whereby inner urban environments, with high thermal mass and low ventilation, absorb and retain heat) amplify and extend the rise in temperatures (especially overnight) (McGeehin and Mirabelli 2001).

In 2003 in Paris many nursing homes and other assistedliving and retirement communities were not air-conditioned, and elderly residents might not have been promptly moved to air-conditioned shelters and rehydrated with fluids (Dhainaut et al. 2004). Hübler, Klepper, and Peterson (2007) have made an attempt to calculate the economic damage of more summer heat days for Germany in the 2071-2100 period, with GDP losses due to reduced labor productivity being more severe than increased hospitality costs.

\subsection{Recent Events in Heat Wave Induced Mortality in Europe}

In this section, we would like to focus on the death toll of heat waves, excluding other aspects from our analysis. The reason for this focus is twofold: (1) despite some methodological

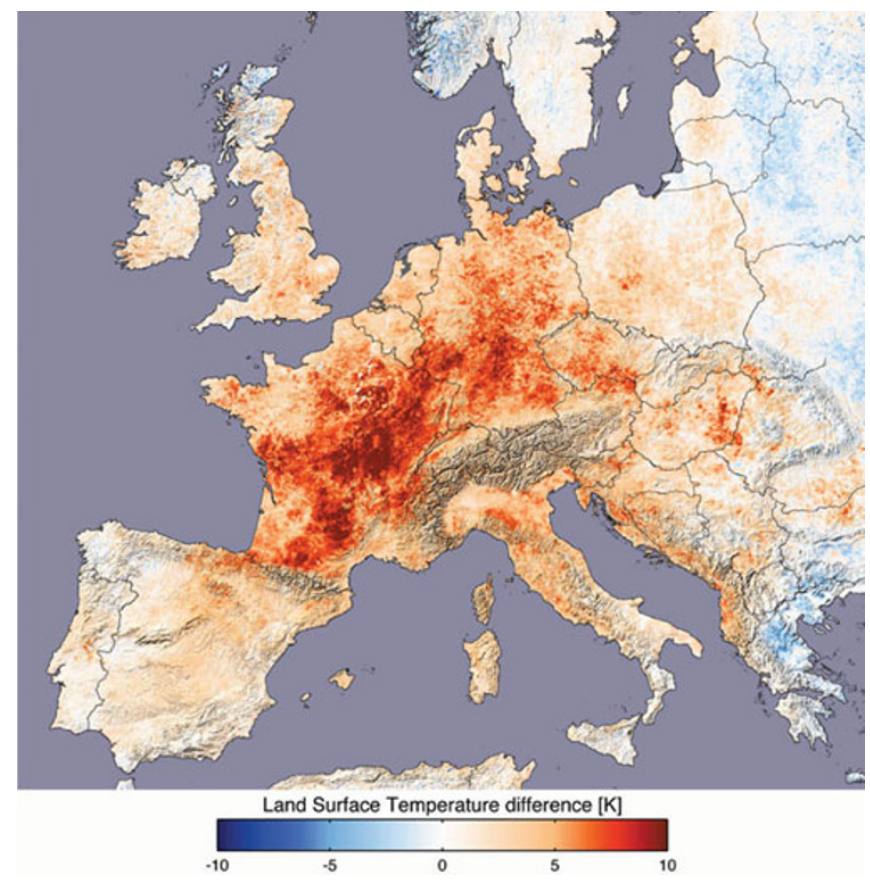

Figure 1. Difference in land surface temperature between 2003 and the average of 2000, 2001, 2002, and 2004, using TERRA MODIS; data range: 20 July-20 August

Source: Stöckli, Simmon, and Herring 2011. difficulties that we address below, counting the victims is a rather clear cut task, and can thus be regarded as a simple but powerful metric for risk analysis; and (2) the loss of human lives is a meaningful measure for detrimental social and economic impacts of extreme weather and, possibly, climate events (Lissner et al. 2011). While one can doubt whether it is methodologically feasible and/or ethically acceptable to translate deaths into monetary equivalents, the unit "victims" can easily be understood in all societies and cultures, whether or not they are used to monetize risk. Besides the loss of human capital, dead people mean a humanitarian loss, a private tragedy, and possibly a social disaster far beyond economic evaluation.

The most important recent heat wave in Europe occurred in July and August 2003. The summer of 2003 was probably the hottest in Europe since AD 1500. Temperature anomalies were $5-10 \mathrm{~K}$ above average summer values (Fink et al. 2004). Maximum temperatures of 35 to $40^{\circ} \mathrm{C}$ were repeatedly recorded and peak temperatures climbed well above $40^{\circ} \mathrm{C}$ (André et al. 2004; Beniston and Díaz 2004).

The heat wave was accompanied by annual precipitation deficits up to $300 \mathrm{~mm}$. This drought contributed to an estimated 30 percent reduction in gross primary production of terrestrial ecosystems over Europe (Ciais et al. 2005). This reduced agricultural production and increased production costs, generating estimated damages of more than $€ 13$ billion (Fink et al. 2004). Unusually large numbers of heat-related deaths were reported in France, Germany, Italy, and other countries. A Pan-European research project came up with more than 70,000 additional dead people due to this event (Robine et al. 2008).

While the summer of 2006 was also very hot, a new record event was the summer of 2010, hitting Eastern Europe and Northern Asia especially hard. Many wildfires occurred in Russia, leading to heavy smoke around big cities, most notably Moscow. Daily maximum temperatures reached $40^{\circ} \mathrm{C}$, and the combined effect of heat and smoke led to 11,000 additional deaths in Moscow alone. For Russia as a whole, the death toll of the 2010 summer heat wave totaled 55,000 people (Swiss Re 2011).

The heat waves of 2003 and 2010 reveal that European societies with very different economic, social, and political settings are vulnerable to extreme weather events. If we choose the metric of mortality, climate risks seem to pose serious problems for European societies, whatever their level of development might be.

\subsection{Future Trends: Heat Waves and Climate Change}

It is impossible to project from a single event to large-scale trends. In particular it is not valid to deduce a shift in the global climate from, say, the European heat waves of 2003 and 2010. Would these two events form our only knowledge base, climate change would be a gamy hypothesis, if not pure speculation. 
But we do have much more than these mega-events to update our expectations regarding the future climate. Deeper analysis of the 2003 heat wave, using longer time series, comes to the conclusion that it can be regarded as extremely unusual under the dominant European climate conditions of the twentieth century, while under conditions of climate change it might become more frequent (Beniston and Diaz 2004). In a Bayesian breakpoint analysis, Siliverstovs et al. (2009) find that since the early 1980s return times of Swiss heat waves decreased by an order of magnitude. While Schär et al. (2004), Stott, Stone, and Allen (2004), and Jaeger et al. (2008) suppose a specific contribution of anthropogenic climate change for recent heat-related weather extremes, Chase et al. (2006) are more careful and try to show that such events occur regularly even under current climatic conditions.

If we focus on time development, changes seem to accelerate. Hansen et al. (2010) have already detected an increase in warm temperature anomalies in the last four decades. This is supported by an analysis of observational data from the 1901-2003 period on temperature extremes (Alexander et al. 2006), revealing that in most stations cold days and nights have decreased, while hot days and nights have increased during the last 100 years.

These shifts in temperature patterns also shift the probabilities of extremes. In Frankfurt am Main (Germany) for example, between 1901 and 2006 the probability of a very high monthly mean temperature in August $\left(T>22^{\circ} \mathrm{C}\right)$ has increased from 0.1 percent to 16.2 percent (Schönwiese 2007).

The majority of meteorologists and climate change experts believe that an increase of average temperatures will lead to an increase in extremes, which also holds for heat waves (Barriopedro et al. 2011; Beniston et al. 2007; Meehl and Tebaldi 2004). The extreme summer of 2003 , very unusual under the climate conditions of the late twentieth century, will become a normal summer at about 2050, and a rather cold summer at around 2100. The IPCC (2007) assumes it to be "very likely" ( $>90$ percent) that the frequency of heat waves will increase over most land areas.

Shifting climate regimes will shift annual weather patterns, which may have an effect on mortality. Mortality is high at both ends of the temperature curve: extreme cold and extreme warm conditions have their death toll. As climate change leads to both warmer winter and summer conditions, the question arises what the net effect of reduced winter and increased summer mortality will be. McMichael, Woodruff, and Hales (2006) assume the net effect to be positive in numbers, i.e. the increase in summer heat deaths will outweigh the reduction in winter mortality.iii

An integrative research project on climate change impacts on Europe (Ciscar 2009; Ciscar et al. 2011) has also assessed the health impacts. Using a SRES A2 scenario, it states that in the 2020s, without adaptation measures and acclimatization, the estimated increases in heat-related mortality are projected to be lower than the estimated decrease in cold-related mortality. The potential increase in heat-related mortality in Europe could be over 25,000 extra deaths per year, with the rate of increase potentially higher in south Central Europe and southern European regions more generally. Physiological and behavioral responses to the warmer climate could have a very significant effect in reducing this mortality (acclimatization), potentially reducing the estimates by a factor of five to ten. By the 2080s, the effect of heat- and cold-related mortality changes depends on the set of exposure-response and acclimatization functions used. The range of estimates for the increase in mortality is between 60,000 and 165,000 (without acclimatization), again decreasing by a factor of five or more if acclimatization is included.

According to the Stern Review, the increase in average annual temperature, and in particular the increases in peak summer temperatures, will result in an increase in heatrelated deaths, mainly in southern Europe. Under a $2^{\circ} \mathrm{C}$ scenario, the number of heat-related deaths in urban areas could increase 2-3 times. Heat-related deaths could reach 50,000 a year under the B2 scenario and 100,000 a year under the A2 scenario in 2100 (Stern 2006, 133).

So far, existing figures for heat wave-related deaths in Europe have been worrying. Given the combined effects of demographic change, urbanization, and climate change, the future will be even more alarming. Of course societies and individual actors can adapt to changing weather conditions. Once they learn from the adverse impacts of past events, they can reduce their vulnerability by a broad range of adaptive measures. Up to now, we have not explicitly addressed this important issue. It is thus time to do so in the next section.

\section{European Heat Wave Coping Strategies}

Heat health warning systems (HHWS) are the most prominent response to heat waves worldwide. The overall aim of an HHWS is to alert decision makers and the general public of impending dangerous hot weather and to serve as a source of advice on how to avoid negative health outcomes associated with hot weather extremes. Typically HHWS are composed of a number of elements, which include weather forecasting, a method for assessing how future weather patterns may play out in terms of a range of health outcomes, determination of heat stress thresholds for action, a system of graded alerts/ actions for communication to the general population or specific target groups about a pending period of heat and its intensity, and advice to government agencies about the possible severity of health impacts.

Since the implementation of the inaugural HHWS in the city of Philadelphia, USA, in 1995, a large amount of international experience has accumulated regarding the development of HHWS. Before 2001, only one HHWS was operational in Europe (Lisbon). In 2000, the World Meteorological Organization chose Rome as a pilot city for the development and implementation of an air-mass based HHWS, which became fully operational in summer 2001. The high numbers 
of heat-related deaths in summer 2003 across Europe, however, resulted in an increase in the number of HHWS. By 2006, HHWS were operational in 16 countries, most of them introduced after the 2003 heat wave, and by 200928 HHWS were operational in Europe (Liukaityte and Koppe 2009).

HHWS vary significantly with respect to the methodologies and operational definitions of warning triggers (e.g., for critical temperature thresholds), both worldwide and in Europe, leaving room for improvement and more coordination (Bassil et al. 2007; Kalkstein, Sherman, and Kalkstein 2009; McGregor et al. 2010; NHS 2006; Nogueira 2005). Hajat et al. (2010) examined 4 commonly used trigger-setting approaches: (1) synoptic classification; (2) epidemiologic assessment of the temperature-mortality relationship; (3) temperature-humidity index; and (4) physiologic classification. They applied each approach in Chicago, Illinois; London, United Kingdom; Madrid, Spain; and Montreal, Canada, to identify those days expected to be associated with the highest heat-related mortality. They found little agreement on which days were identified as most dangerous among the various approaches. In general, days identified by a temperature-mortality approach have been associated with the highest excess mortality.

Heat health warning systems are often part of a wider heat plan. These heat plans embrace the HHWS itself, but additionally consider a whole set of strategy elements: education and awareness raising; heat event preparedness and guidance on heat avoidance actions and heat risk governance; a communication plan, a program of evaluation; a health surveillance system; and advice on longer term strategies for reducing heat risk. European heat plans vary widely in structure, partner agencies, and specific interventions. The majority of the existing heat-health action plans are organized on a national level (England, France, Portugal, and Hungary) with regional components. But several are implemented on a regional and local level (Catalonia, Spain; Lazio, Italy; Federal States of Germany). Almost all systems were initiated and designed by the ministry of health as the lead agency and all had an official link to the national meteorological service. The systems in Italy, France, and Hungary had a legal basis and Hungary, England, and Catalonia described a link to the national disaster plan. Most heat health warnings in Europe are issued by the national meteorological offices. The communication campaigns are mostly the responsibility of the ministries or departments of health, or institutes of public health, in collaboration with the health services. Behavioral and medical advice is launched through health services, general practitioners, and pharmacies. Hospital and care home managers, as well as their staff, ensure the implementation of specific measures in their facilities. General practitioners and health centers, as well as social services, are often the main partners responsible for the care of people at risk (Matthies

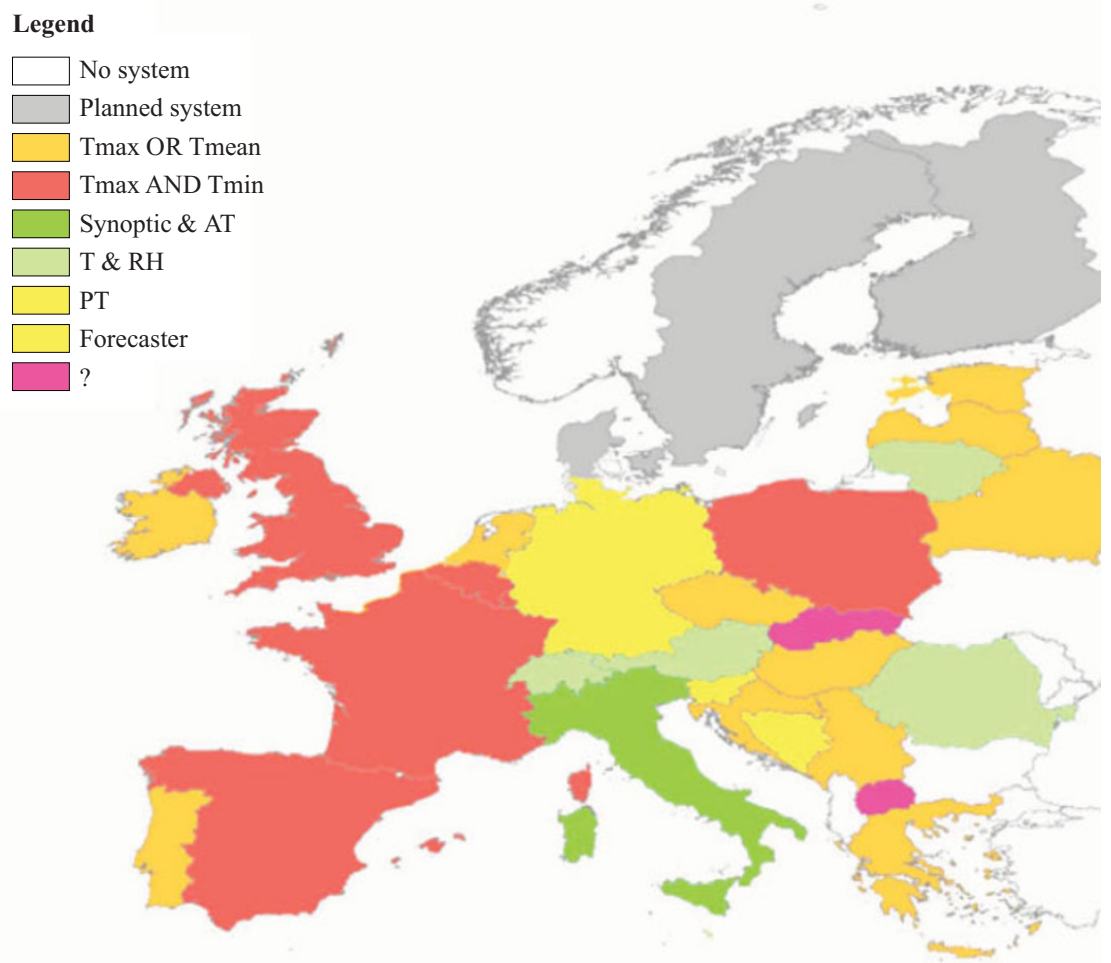

Figure 2. Operational Heat Health Warning Systems (HHWS) in Europe (status 2009); The figure shows the different methodological thresholds used for initialization of early warning. Legend: Tmax: maximum temperature; Tmean: mean temperature; Tmin: minimum temperature; AT: apparent temperature; T: Temperature; RH: relative humidity; PT: perceived temperature; ?: not known.

Source: Liukaityte and Koppe 2009 . 
and Menne 2009). Table 1 gives an overview of different measures and strategies that existing HHWS and heat plans include.

While it is difficult to assess the efficiency of these systems, some agencies report about their interventions at the end of the summer season. A case study of the French early warning system, comparing the mortalities of the 2006 heat wave to that of 2003 concludes that the implementation of HHWS in France after the 2003 event did contribute to a reduction in the numbers of victims (Fouillet et al. 2008). In contrast, the death toll of the summer 2006 heat wave in many other European countries with HHWS in place shows that there are still gaps in implementation, and that many European countries have not yet developed sufficient actions (WHO Europe 2008a).

Triggered by the European heat wave in 2003, several research projects have been launched that do address heat wave impacts - among other climate change impacts - on European societies and their ecosystems. One of these projects, EuroHEAT, was coordinated by the Global Change and Health program of the WHO Regional Office for Europe and co-funded by the EU Directorate General for Health and Consumers. The project quantified the health effects of heat in European cities and identified options for improving the preparedness and response of health systems to protect health from heat waves. Its activities contributed to the implementation of the Declaration of the Fourth WHO Ministerial Conference on Environment and Health and of the European Commission's Environment and Health Action Plan.

One of the core findings of the project was that the adverse health effects of heat waves are largely preventable if certain conditions are met (WHO Europe 2008b). One outcome of these activities is the web-based heat wave forecasting tool called EuroHEAT (http://www.euroheat-project.org/dwd/ index.php). This tool is based on the Ensemble Prediction Systems (EPS) of the European Centre for Medium Range Weather Forecasts (ECMWF) and consists of a 50 member ensemble. EPS simulates possible initial uncertainties by adding, to the original initial conditions, small perturbations within the limits of uncertainty of the initial data. This creates an ensemble of slightly different initial conditions. Each ensemble member is then used as starting point for a forecast. Instead of one forecast with a specific starting date and lead time, an EPS produces an ensemble of forecasts. The skill of the EPS forecast is very good for short lead times, but decreases significantly with increasing lead times.

Table 1. Measures and strategies in existing Heat Health Warning Systems (HHWS) and heat plans

\begin{tabular}{|c|c|c|}
\hline Measure, strategy & Level of implementation & Comments \\
\hline Media announcements (radio, television) & +++ & Provide general advice on heat stress avoidance to general public \\
\hline Bulletin or webpage & +++ & May be restricted access, to relevant professionals or accessed by anybody \\
\hline Leaflets & ++ & $\begin{array}{l}\text { General advice, and advice for nursing home managers. Often distributed at } \\
\text { beginning of the summer via health centres, and places where vulnerable } \\
\text { people may be }\end{array}$ \\
\hline Telephone help-line & ++ & $\begin{array}{l}\text { Either a dedicated telephone service is opened (e.g. Heatline in Portugal) or } \\
\text { people are encouraged to phone a pre-existing general health advice line } \\
\text { (e.g. NHS Direct in the UK) }\end{array}$ \\
\hline Opening of cooling centres & ++ & $\begin{array}{l}\text { Some evidence that cooling centres not used by high-risk individuals, but } \\
\text { used by low-risk individuals }\end{array}$ \\
\hline $\begin{array}{l}\text { Alert to hospital emergency rooms, } \\
\text { ambulance services }\end{array}$ & + & $\begin{array}{l}\text { Used to improve operational efficiency (e.g. if need to deploy extra staff). } \\
\text { Needs to be based on local information and carefully evaluated }\end{array}$ \\
\hline $\begin{array}{l}\text { Home outreach visits to vulnerable } \\
\text { persons }\end{array}$ & + & $\begin{array}{l}\text { Important but usually expensive. Use pre-existing networks of volunteers } \\
\text { (e.g. Buddy systems in Philadelphia), or professionals (e.g. social workers). } \\
\text { Requires some registry of vulnerable people }\end{array}$ \\
\hline $\begin{array}{l}\text { Evacuation of vulnerable persons from } \\
\text { their homes to cooling centres }\end{array}$ & + & $\begin{array}{l}\text { Using a registry of vulnerable people, who are visited at home, and } \\
\text { evacuated, if necessary }\end{array}$ \\
\hline Outreach to homeless & + & $\begin{array}{l}\text { High-risk group in southern US (11 homeless people died in heatwave in } \\
\text { Phoenix, July 2005) }\end{array}$ \\
\hline $\begin{array}{l}\text { Electricity companies cease disconnection } \\
\text { for non-payment }\end{array}$ & +++ & $\begin{array}{l}\text { Utility companies have initiated and financially supported HHWS in the US. } \\
\text { Most important where population relies on heavily air conditioning (as in } \\
\text { the US) }\end{array}$ \\
\hline $\begin{array}{l}\text { Water companies cease disconnection for } \\
\text { non-payment }\end{array}$ & + & \\
\hline Fan distribution & ++ & $\begin{array}{l}\text { Fans are effective when they circulate cooler air, but not above temperatures } \\
\sim 37^{\circ} \mathrm{C}\end{array}$ \\
\hline
\end{tabular}

Source: Kovats and Ebi 2006. 
EuroHEAT is a good example of a social learning process derived from recent heat waves. It is European in scope, and integrates different weather forecast models. There is no heat action plan underlying the heat early warning system, but with respect to a Pan-European heat wave risk governance structure this could be changed.

\section{Towards Heat Wave Risk Governance}

As we have seen in the previous sections, heat waves already pose a serious threat to European societies, and it is expected that climate change will increase the frequency and the intensity of European heat waves. Many agencies, including weather forecasting organizations, have reacted and developed heat health early warning systems. In principle, the heterogeneity of methods and procedures followed is not a problem. Regional and local conditions vary and lead to different vulnerabilities. In addition, there is always some path dependency in the development of HHWS, given the traditions and the capacities of national weather services. Against this background, the plurality of warning systems in Europe is an asset, and one can refer to principles of subsidiarity and federalism ${ }^{\text {iv }}$ in order to justify it. Coordination, cooperation, and learning have to be improved, however, in order to avoid additional heat wave deaths. In addition, forecasting and warning systems have to be based on a comprehensive risk analysis, as weather baselines can be expected to shift due to climate change, and as societies have to get prepared in order to assess realistically the potential damages of more frequent heat waves.

Thus the question arises: How might an improved heat wave risk governance architecture for Europe look like that capitalizes on the flexibility of systems and variety of national approaches, one that at the same time ensures comparability, cooperation, and a comprehensive analysis of changing risk conditions? First of all, we think it appropriate to characterize what we mean by risk governance, and why we assume it to be indispensable in the case of heat waves in Europe, before we give an outline of such an architecture.

\subsection{Risk Governance}

While risk management refers to all measures that deal with a given risk, the term risk governance explicitly takes into account the complexity of risks as well as the heterogeneity of the social institutions and organizations that deal with them. We have outlined the necessity of such a governance approach to risk in programmatic terms in another paper (Shi et al. 2010). Here we would like to apply the approach to heat waves.

Risk governance deals with the identification, assessment, management, and communication of risks in a broad context (IRGC 2005, 2008; Shi et al. 2010). It includes the totality of actors, rules, conventions, processes, and mechanisms involved in managing risks, is concerned with how relevant risk information is collected, analyzed, and communicated, and evaluates how management decisions are taken. It applies the principles of good governance (such as transparency, effectiveness, efficiency, and acceptability) to the domain of risk research and risk management (Jaeger et al. 2001).

The benefits of good risk governance are quite clear. It avoids inequitable distribution of risks and benefits between countries, organizations, and social groups, deals with different approaches to assessing and managing the same risk, considers political boundary conditions and trade-offs, and takes into account economic costs and public perceptions.

On a national scale, governance describes structures and processes for collective decision making involving governmental and nongovernmental actors (Nye and Donahue 2000). Governing various choices in modern societies is seen as an interplay between governmental institutions, economic organizations, and civil society actors (such as NGOs). At the global level, governance embodies a horizontally organized structure of functional self-regulation that encompasses state and non-state actors and brings about collectively binding decisions without superior authority (Rosenau 1992). In this perspective, non-state actors play an increasingly relevant role and become more important, since they have decisive advantages of information and resources compared to single states.

But governance is not confined to strictly political issues or levels. The important point for our analysis is that governance approaches are meaningful and necessary if simple coordination measures of political bodies do not suffice, but nonpolitical actors are essential for the problem definition and solving. Heat waves transcend the capacity of government agencies, as knowledge and information providers (science, weather services), and economic and other social actors are required in order to generate and provide relevant knowledge as well as to design and implement meaningful action. We thus argue that risk governance is necessary for coping with heat waves in Europe.

\subsection{Risk Governance Framework for Heat Waves}

Risk governance includes five major elements: a preassessment of risk, risk appraisal, risk judgment, risk management, and risk communication (IRGC 2005, 2008). It is important to link these elements in a meaningful and sequential way (Figure 3). While these steps do have a clear time sequence, it is also important to see that recursive loops are necessary as well.

We start from the sequential loop of the above mentioned elements, and enrich them with respect to heat wave risks as we have discussed above. It is worth noting that risk governance sits at the interface of analysis and understanding on the one hand, and decision making and action on the other. This holds in particular when scientific questions play a key role in understanding specific issues. In the case of heat waves, climate change induced risk amplification is a good example. 


\subsubsection{Heat Wave Risk Pre-Appraisal}

The first step for any analyst of risk is to come up with a scoping of heat wave risks in the context of other risks, and a qualitative assessment of the framing of heat waves. Given the fact that heat wave risk analysis has become a research and, in part, an action area in its own right, this step might seem superfluous. But as it is always helpful to rethink routine assumptions of certain communities, it is necessary to readjust the underlying risk definitions for heat waves from time to time, to compare them with other risks (not only those associated with climate change), and to find out how important social stakeholders (for example policy branches, business communities, NGOs) understand the issue and how they want to deal with it. In the same line of thought, existing regulations for heat wave management have to be briefly (and repeatedly) reviewed in order to adapt risk governance schemes to new developments.

This would already hold if heat waves could be perceived as natural climate variations exclusively, as some extreme events in the range of "normal" stochastic extremes might shift the way decision makers or the wider public perceives them (for example shifting from nuisance to disaster). This prospect is even more likely as heat waves become more frequent and intense due to anthropogenic climate change, and as risk baselines will shift measured either as a frequentist return period or as a Bayesian prior belief. ${ }^{v}$

For that same reason, a heat wave pre-appraisal also needs to identify the climate discourse of a given region or country. ${ }^{\mathrm{vi}}$ It makes a huge difference whether, for example, the climate discourse is focusing on the attribution question-is there anthropogenic climate change or not-, or whether it has moved to a next phase in which different solutions are debated (Reusswig 2010). In that sense, one can argue that the European heat wave of 2003 has helped to bring about such a new climate change discourse, and that the establishment of heat health warning systems in many parts of Europe took place under the auspices of this new climate change discourse. In contrast, we find that in Russia climate change is much debated and more controversial - as it is in the U.S. - and that this oil and gas exporting country finds it difficult to accept officially the ongoing anthropogenic global climate change as a risk. Instead, leading Russian politicians as well as some Russian climate scientists either neglect climate change altogether, or assess it as having a net beneficial effect on the Russian economy. After the severe heat wave that hit Russia in summer 2010 the perception may change: Still Russian meteorologists, looking at instrumental records in Moscow of the last 130 years and a Gaussian probability distribution, came to the conclusion that this extreme event would occur only every 5,000 years; but on the other hand prominent politicians and experts put the extreme event in the context of anthropogenic climate change (Shuster 2010).

\subsubsection{Heat Wave Risk Appraisal}

Risk appraisals are the cognitive core elements of any risk governance scheme. The appropriate assessment of what is creating the risk, and how, is a central prerequisite for any practical risk management strategy. There are two major

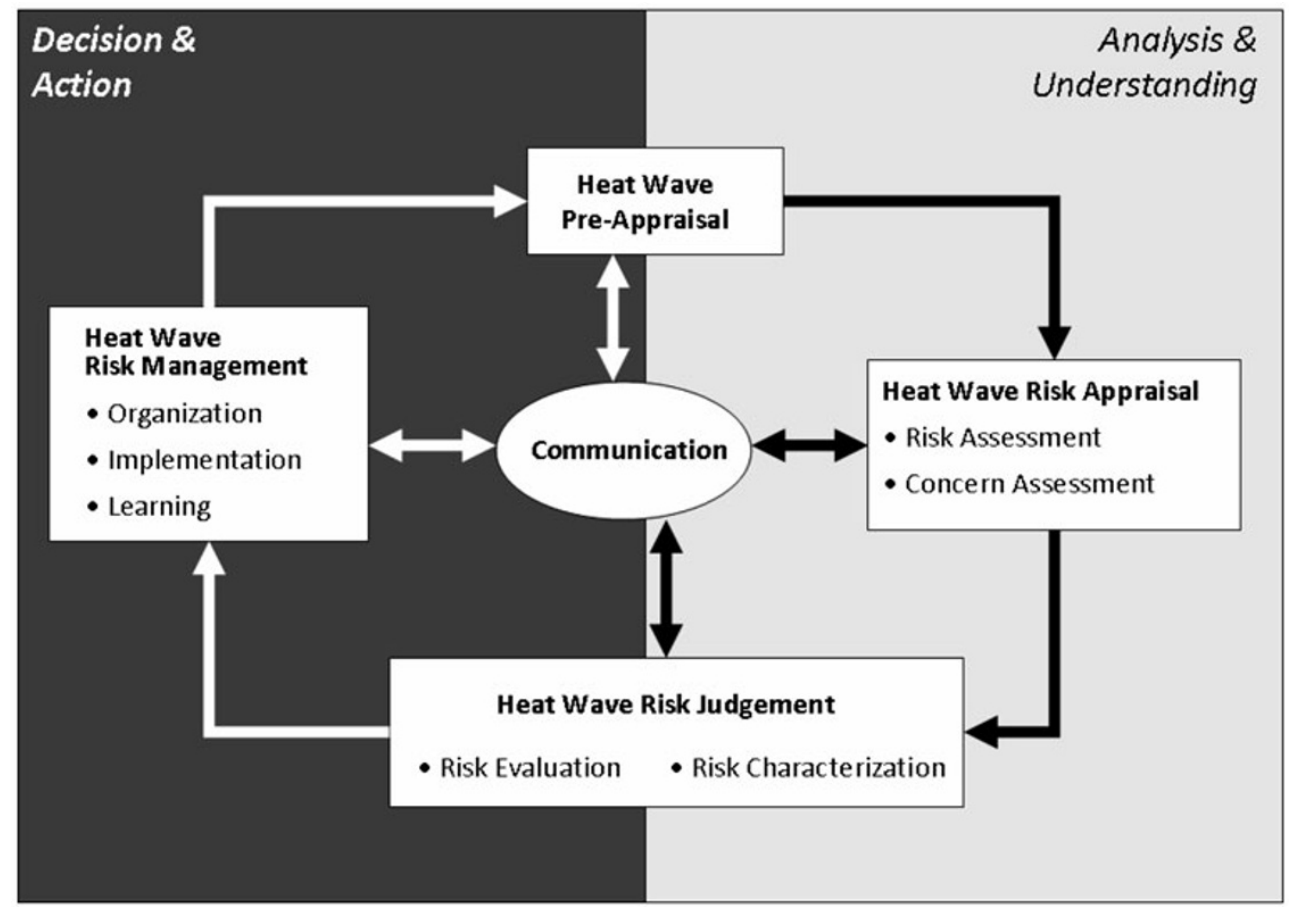

Figure 3. Schematic elements of a heat wave risk governance framework

Source: Modified after IRGC 2005. 
aspects we would like to highlight here: risk assessment and concern assessment.

The risk assessment component deals with questions of probability and potential damage, or adverse effects. The systematic screening of historical records of heat waves in particular regions is crucial, but scientific findings that test for future developments, changing baselines, and interactions of different risks are also imperative. Case studies of historic events provide important insights into the vulnerability of particular systems, regions, and social groups. They help to establish a common knowledge base for cause-effect relations that have to be addressed when it comes to designing management options.

An important question is what scientific, technical, and analytical approaches, knowledge, and expertise should be used to (better) assess the adverse impacts of heat waves. In this context it is important to remember that existing heat wave management practices can be seen as "incorporated knowledge," schemes that are based upon some underlying risk assumptions that are not necessarily made transparent, may be because most agents take them for granted. If baselines for heat waves shift due to climate change, such taken-for-granted assumptions underlying management practices have to be reviewed critically, and tested against scenarios for different futures. In this respect it is crucial to become aware of the theories, organizations, and persons that - for any given region - are or may become relevant to assessing the risk of heat waves, such as climatologists, medical specialists, social workers, key administrative staff, and social scientists. Providing a flexible and adaptive knowledge base is crucial for risk governance - both with respect to theoretical concepts and to organizations and persons.

In Europe, the 2003 heat wave triggered much research as well as the establishment of different early warning systems at the national and local levels. Despite a flurry of activities concerning climate change and a growing interest in the research community, heat wave risk assessments remain fragmented, and basic tools for facilitating good decision making are lacking (Corfee-Morlot et al. 2011). A Europewide approach to improve the knowledge base for heat waverelated risk appraisal is needed. We suggest an initiative to integrate the empirical findings and, most of all, the methods of short-term research, assessment, and monitoring activities (Fink et al. 2004; Koppe et al. 2004; Kosatsky and Menne 2005; Michelozzi et al. 2005; Robine et al. 2008) into existing institutionalized activities, whereby sectoral and standardized assessments have to be accelerated in specific domains (Lissner et al. 2011). We suggest the International Disaster Database (EM-DAT) at the Center for Research on the Epidemiology of Disasters (CRED) at the School of Public Health in Louvain's University to be the best suited institution for this purpose (http://www.emdat.be/). The European Union seems the most appropriate organization to fund the integration of findings and the transfer methods of leading European research groups into the EM-DAT monitoring scheme. It could also usefully fund consulting and outreach capacities at
CRED in order to provide national and local risk managers with relevant information of how to create regionally adapted risk-related information bases. It is important to involve WHO Europe with its head office in Copenhagen in the creation of such an activity for capacity building in order to improve the salience of health-related information.

Risk assessments deal with probabilities and potential damages, but they do not cover the whole range of a comprehensive risk appraisal. We additionally suggest a concern appraisal, addressing the social representation of heat wave risks. While from a purely natural science point of view it might seem unnecessary or even detrimental to ask for social concerns in addition to the classical dimensions of risk, from a risk governance perspective it is crucial to do so. What are the public's concerns and perceptions of heat waves? What is the social response to heat wave risks? Is there the possibility of political mobilization or potential conflict? What roles do existing institutions, governance structures, and the media play in defining public concerns? Which socioeconomic damages can be expected from heat waves? Questions such as these have to be answered in order to design a viable management strategy. They reflect the fact that the results of climate science do not influence a society's climate discourse per se. Only what passes the filter of social amplification or downplay, for which the mass media representation of (past) heat waves and climate change in general is crucial, meaningfully affect public discourse and understanding of the problem.

Thus we contend that the CRED updated monitoring and outreach activity should be accompanied by a mass media analysis unit that collects and critically analyzes European mass media coverage of heat wave-related events. In cases of mass media misrepresentation of facts and causal attributions, CRED could also inform local and national risk managers about improved information strategies.

\subsubsection{Heat Wave Risk Judgment}

While risk assessments make up the core of the scientific analysis and understanding of risks, risk judgments are situated at the interface between analysis and action. The term judgment explicitly refers to the dimension of valuation in all assessments and aims at a more conscious, systematic, and transparent mode of risk evaluation. Risk judgment has two major components: risk characterization and risk evaluation.

Risk characterization, lending itself more to the analytical side, focuses on the health and socioeconomic effects of heat waves and tries to qualify different qualitative and quantitative profiles of risk situations. As we have seen, hot spell and heat wave mean different things for different locations, depending on the existing adaptive capacity of established behaviors and infrastructures. This means that heat wave risk profiles differ across and between regions.

As risk profiles are area specific, their realization depends on area profiles that identify the vulnerable regions, sectors, and groups in a given region. This again requires a sound book-keeping with respect to past heat wave events in the 
same region. For this purpose official statistics, past mass media reports, and oral or other reports from people affected or responsible for risk management are helpful. At the same time, comparisons with past experiences of other regions deliver valuable insights, as climate change will shift the baselines for risk assessments. The method of climate analogies is a very useful tool here (Hallegatte, Hourcade, and Ambrosi 2007; Hallegatte and Corfee-Morlot 2011).

This also means that heat wave management schemes in place elsewhere are also relevant for assessing and improving a specific area's risk profile. There are many studies available - again most of them triggered by the 2003 heat wavethat compare early warning systems and other heat wave management systems. In order to enable risk managers to learn from good practice, the European Union should fund a continuous effort to compare these systems in a coherent manner, building upon existing experience both from European research projects and from specialized organizations such as WHO. We propose to institutionalize such a heat wave management monitoring activity at The Monitoring and Information Centre (MIC), a branch under the auspices of the European Commission's Mechanism for Humanitarian Aid and Civil Protection (http://ec.europa.eu/echo/civil protection/civil/prote/mic.htm).

Risk evaluation makes up the second pillar of risk judgment, lending itself more to the decision and action side of risk governance. Here normative and evaluative aspects do come explicitly to the fore. What are the values at risk in case of heat waves? What ethical problems or conflicts arise? Which potential damages are tolerable and acceptable, and for whom? What does a disaster mean for particular sectors or groups, especially for vulnerable individuals and communities who are often neglected, such as the homeless or tourists? What costs - in a wider sense, including not only monetary but also organizational and psychological costs - are attached to particular risk reduction options, and who will have to bear them? Are there any co-benefits from heat wave risk reduction options, and where/to whom do they accrue?

It is important to deal with these questions in an open, transparent manner at this stage of the risk governance process. If these political questions are not addressed early enough - and many scientists tend to leave them to politicians - conflicts over management priorities and the allocation of scarce resources will become much more difficult later.

As a result of risk characterization and risk evaluation, the feasible management option space for a given region should become clear. This option space should not only cover what could be done in case of upcoming heat waves, but also determine what are the most effective and efficient measures with which to cope with climate perturbations.

\subsubsection{Heat Wave Risk Management}

The management of heat waves clearly is the practical core of risk governance, and the reason and goal for the whole opera- tion. Risk management involves the design and implementation of the actions and remedies required to avoid, reduce, transfer, or retain the risks. Questions of organization, implementation, and learning are at its heart. Risk management includes the generation, assessment, evaluation, and selection of appropriate risk reduction options as well as implementing the selected measures, monitoring their effectiveness, and reviewing the decision if necessary.

As a first step, the definition and set-up of the risk management process and the involved actors and organizations are crucial. Who should be involved, who can bring in specific competences and responsibilities, and what will be the lines of decision making and communication? In this domain it becomes clear why the term "risk governance" is more appropriate than "risk government." Government processes refer to more or less hierarchical structures in public agencies, where the assigned staff and its communication and decision lines are clear-at least in principle. While government bodies (such as municipal departments or the police) do play an important role in risk management, they are not the only relevant actors. In the case of managing heat wave risks, the required set of agents comprises hospitals, medical doctors, retirement home managers, landlords, urban planners, facility managers, entrepreneurs, civil society organizations, and active citizens at large. It is impossible to organize these heterogeneous actors in a top-down manner, as government organizations typically do. Instead, cooperative forms of coordinated action are required, combining elements of top-down control with those of motivation, consultation, and voluntary cooperation. The handling of these hybrid forms of coordinated action requires skills in governing (not commanding and controlling) social networks rather than heading a single agency. Experienced individual agency heads may very well be qualified to govern these networks, but mostly due to additional skills acquired through long-term, on-the-job experience.

Heat wave risk management needs an early warning system. As we have seen, such systems operate in most European countries. Yet they are based on different methods. Heat waves can occur locally, and heat wave vulnerabilities vary considerably between cities and regions. It is thus reasonable to follow different approaches across Europe. But in view of trans-boundary heat waves, as well as in view of the allocation of European organizational capacity and funds, a coherent European early warning culture has to emerge.

National weather services have been the major drivers of existing heat wave early warning systems, and their respective meteorological approaches have shaped the multitude of currently co-existing event risk definitions and thresholds for specific actions. While plurality may be a strength, fragmentation is not. Needed is a nested European early warning system that evolves from existing systems, accompanying the other integrative governance efforts we have mentioned so far. The Europe-wide, web-based prognostic tool EuroHEAT, based upon ensemble predictions for heat waves, could be the nucleus for the final integration version of these efforts. It is 
crucial that the development process of a Pan-European heat wave early warning system is not driven by meteorological considerations (and agencies) alone. It is essential to keep in mind that an early warning system is not primarily an addon service of meteorological offices, but the first step in a disaster management process. As such, other actors must be involved, bringing in all aspects of relevant information, timelines, degree of details, necessary supporting data and interpretation materials, and understandable communication.

The next broad step is to develop locally/regionally adopted measures to reduce exposure to heat waves. As many victims die before they reach the hospital, such a step is crucial in order to reduce mortality. There are multiple ways of reducing individual heat exposure. This includes individual behavioral measures, short-, medium-, and long-term housing measures, and long-term improved urban planning, building design, and transport and energy policies. Short-term measures include advice on behavior, provisioning of access to cool spaces, as well as the allocation of mobile evaporation coolers and room air conditioners. Medium-term measures include increasing the albedo of the building envelope, external shading, insulation, decreasing the internal heat load, the provisioning of passive cooling technologies, and efficient active cooling. Long-term measures encompass the adaptation of building regulations, urban planning, land-use changes, and mitigation of climate change (Matthies and Menne 2009; U.S. EPA 2006; WHO Europe 2008a, 2008b).

It is clear that this very broad package of measures not only asks for the coordination of a multitude of actors, but also for the integration of heat wave risk management into other policy and planning areas. This implies that different processes and timelines are involved. While information campaigns for triggering behavior changes can be implemented rather rapidly and need but a small network of agents, changing building legislations and codes may take several years, and requires the involvement of national agencies, governments, political parties, and parliaments, among others. Here again, a European focal point for heat wave risk governance could help to push national legislations, e.g. by providing facts, experience, and future impact scenarios.

While a general information campaign is indispensable, more specialized and probably more personalized information is needed in order to reach particular target groups, such as isolated elderly or homeless people. Social scientists and communication specialists will be needed to tailor information to their needs and capacities, and other actors relevant to the everyday life practices of those groups (health care organizations, health insurance agencies, social assistance agencies, local nodal points, such as shelters, shopping centers, or meeting rooms) must be engaged in the effort. Mass media campaigns not only require sound information, they also need to be communicated by credible and accepted people; the same holds true for personalized information, in which case a specialized staff needs extra training. vii

A next necessary step is to develop emergency plans for those instances when a particular threshold of the early warning process has been passed. Again, the relevant actor network has to be first defined, and communication and decision procedures, together with responsibilities, have to be agreed upon. An affected region or city has to identify and assign cooling rooms that the general public can easily access (such as public buildings); it has to design and implement emergency action plans for hospitals, retirement homes and kindergartens; it should suspend shut-offs of utilities for individuals during heat events; and it should reschedule public events to avoid large outdoor gatherings when possible. Businesses in the region whose employees work outside should also develop behavior guidelines and implement emergency plans. Public authorities should install (and communicate) phone hotlines, and national weather services, together with telecommunications operators, should offer specialized information for mobile phones.

This bundle of measures will not only vary from region to region, according to the outcomes of the risk judgment phase. It will also vary over time, given the learning process due to implementation experiences and new ideas from elsewhere. Monitoring the outcomes of management plans and the provisioning of learning capacities (for instance extra staff members, or extra time reserved for evaluation exercises) is a necessary step towards a resilient, learning network of heat risk governance agencies.

\subsubsection{Risk Communication}

Finally, the critical importance of communication should be emphasized briefly_last but not least. Its role has already been mentioned several times in this article. This is not accidental. In fact, communication is an essential factor for successful risk governance (Renn 2008) as well as for many climate change adaptation situations (Hinkel et al. 2009). This holds for two sets of reasons. On the one hand, the heterogeneity of actors at various scales makes it essential to communicate in order to create and maintain action capacity. On the other hand, the variety of agencies and publics that heat risk governance has to address requires flexible forms of communication in order to get heard and understood.

One might call the first aspect internal communication (within the actor network), while the second one refers to external communication with those institutions and groups that provide necessary information or are addressed as potential users. While it might be impossible to institutionalize these two strands in a separate organization, it is indispensable that all actors involved in the governance network should be aware of the necessity to get the communication side right.

\section{Conclusion}

The study of recent evidence of heat wave-related mortality data indicates that while economic wealth and technological capacity might be a necessary condition for adequately 
coping with adverse climate change effects, they are hardly sufficient. The death toll of recent heat waves in developed countries has been remarkably high, contradicting the common assumption that scoring high in economic and technological indicators automatically leads to low vulnerability to weather extremes. Due to climate change, heat waves can be expected to become more frequent, adding to the challenge posed by climate impacts and raising the question of the adaptive capacity of even the developed countries to climate change.

After the 2003 heat wave, many European countries underwent a remarkable process of social learning and implemented heat health warming systems. But phenomena like the death toll of the summer 2006 heat wave in many European countries with heat health warning systems in place demonstrates that there are still gaps in implementation, and that many European countries have not yet developed sufficient action plans and responses.

Questions of awareness, preparedness, organizational issues, and actor networks have to be addressed in a proactive and focused manner in order to decrease future heat wave damages considerably. We propose practical consequences for heat wave adaptation measures by adopting a risk governance framework that can be universally applied as it is sufficiently flexible to deal with the multi-level and often fragmented reality of existing coping measures. The proposed risk governance framework can give structure to processes of social learning that decrease the vulnerabilities of societies to weather extremes, whatever their future frequency may be.

\section{Acknowledgment}

The authors thank Jakob Müller and Carolin Rosenkranz for their administrative support.

\section{Notes}

i According to our simplified ontology we understand by natural systems mainly uncontrolled ecosystems, such as wild living animals, oceans, or wild forests; by semi-natural systems mainly controlled systems such as managed forests, agricultural systems, or the world's livestock; by technical systems such human designed and managed artifacts as houses, machines, or technical infrastructures (roads, power lines, or similar constructions); and by social systems we intend human institutions and societies, including human agents and their bodies. We are well aware that this is a somewhat arbitrary categorization, as there are gradual differences. Nevertheless we need some ideal types to clarify what we focus upon.

ii As most human dominated ecosystems are less diverse than natural ones (the species composition of natural rain forests compared to that of nearby plantations, for example), they are less resilient and show a greater dependency on external intervention, such as provisioning of nutrients or water. This makes human-dominated ecosystems usually more vulnerable than natural ones.

iii Demographic effects will aggravate climate change risks, as the proportion of the elderly in Europe will increase dramatically. In 2004, 75.3 million of the 456.8 million EU 25 inhabitants were older than 65 , and 18.2 million older than 80. In 2050, EU 25 will have about 453.8 million inhabitants, but 133.3 million will be $65+$, and 49.9 million will be $80+$ (DG ECFIN 2006).

iv We refer to the European notion of federalism that focuses on the decentralist perspective of a federal structure, as for example realized in Germany, in contrast to a centralist political and administrative tradition, for which in Europe France still provides a good example.

$\mathrm{v}$ Frequentists define probabilities on the basis of historical frequencies (e.g. tumbling a dice ideally an infinite number of times), whereas Bayesians define them as subjective measures of uncertainty. There is, therefore, a frequentist and a Bayesian concept of probability.

vi "A climate change discourse is a thematically focused and (more or less) coupled sequence of publicly visible arguments in various contexts (or framings) that different social actors are engaged in, in order to influence (1) one another, (2) specific boundary conditions of social action (such as politics), and (3) the general public so that the resource endowments, interests and worldviews of the speaking actors have a higher chance to prevail in the social interpretation and individual or collective decision making processes" (Reusswig and Lass 2010, 158).

vii If funds for heat wave risk management do not allow for specialized permanent staff, it might be equally effective to train other staff that communicates with vulnerable target groups on a regular basis.

\section{References}

Alexander, L.V., X. Zhang, T. C. Peterson, J. Caesar, B. Gleason, A. M. G. Klein Tank, M. Haylock, D. Collins, B. Trewin, F. Rahimzadeh, A. Tagipour, P. Ambenje, K. Rupa Kumar, J. Revadekar, and G. Griffiths. 2006. Global Observed Changes in Daily Climate Extremes of Temperature and Precipitation. Journal of Geophysical Research 111, D05109. DOI:10.1029/2005JD006290.

André, J.-C., M. Déqué, P. Rogel, and S. Planton. 2004. The 2003 Summer Heatwave and Its Seasonal Forecasting. Comptes Rendus Geoscience 336 (6): 491-503.

Barriopedro, D., E. M. Fischer, J. Luterbacher, R. M. Trigo1, and R. García-Herrera. 2011. The Hot Summer of 2010. Redrawing the Temperature Record Map of Europe. Science 332 (6026): 220-24. DOI:10.1126/science.1201224.

Bassil, K., D. C. Cole, K. Smoyer-Tomic, and M. Callaghan. 2007. What is the Evidence on Applicability and Effectiveness of Public Health Interventions in Reducing Morbidity and Mortality during Heat Episodes? Vancouver, BC: National Collaborating Centre for Environmental Health.

Beniston, M., and H. F. Díaz. 2004. The 2003 Heatwave as an Example of Summers in a Greenhouse Climate? Observations and Climate Model Simulations for Basel, Switzerland. Global Planetary Change 44 (1-4): 73-81.

Beniston, M., D. Stephenson, O. Christensen, C. Ferro, C. Frei, S. Goyette, K. Halsnaes, T. Holt, K. Jylhä, B. Koffi, J. Palutikof, R. Schöll, T. Semmler, and K. Woth. 2007. Future Extreme Events in European Climate: An Exploration of Regional Climate Model Projections. Climatic Change 81 (Supplement 1): 71-95.

Bouwer, L. M. 2011. Have Disaster Losses Increased due to Anthropogenic Climate Change? Bulletin of the American Meteorological Society 92 (1): 39-46.

Chase, T. N., K. Wolter, R. A. Pielke Sr., and I. Rasool. 2006. Was the 2003 European Summer Heat Wave Unusual in a Global Context? Geophysical Research Letters 33, L23709. DOI:10.1029/2006 GL027470.

Ciais, Ph., M. Reichstein, N. Viovy, A. Granier, J. Ogee, V. Allard, M. Aubinet, N. Buchmann, C. Bernhofer, A. Carrara, F. Chevallier, N. De Noblet, A. D. Friend, P. Friedlingstein, T. Grünwald, B. Heinesch, P. Keronen, A. Knohl, G. Krinner, D. Loustau, G. Manca, G. 
Matteucci, F. Miglietta, J. M. Ourcival, D. Papale, K. Pilegaard, S. Rambal, G. Seufert, J. F. Sousanna, M. J. Sanz, E. D. Schulze, T. Vesala, and R. Valentini. 2005. Europe-Wide Reduction in Primary Productivity Caused by the Heat and Drought in 2003. Nature 437 (7058): 529-33.

Ciscar, J.-C., ed. 2009. Climate Change Impacts in Europe. Final Report of the PESETA (Projection of Economic impacts of climate change in Sectors of the European Union based on boTtom-up Analysis) Research Project. Luxembourg: Publication Office of the European Union.

Ciscar, J.-C., A. Iglesias, L. Feyen, L. Szabó, D. Van Regemorter, B. Amelung, R. Nicholls, P. Watkiss, O. B. Christensen, R. Dankers, L. Garrote, C. M. Goodess, A. Hunt, A., Moreno, J. Richards, and A. Soria. 2011. Physical and Economic Consequences of Climate Change in Europe. PNAS (Proceedings of the National Academy of Sciences of the United States of America) 108 (7): 2678-83.

Conti, S. 2011. Heat Wave and Mortality of Elderly. In Encyclopedia of Environmental Health, edited by J. O. Nriagu, 113-34. Riverport Ln: Elsevier Science Ltd - Elsevier Science \& Technology.

Corfee-Morlot, J., I. Cochran, S. Hallegatte, and P.-J. Teasdale. 2011. Multilevel Risk Governance and Urban Adaptation Policy. Climatic Change 104 (1): 169-97. DOI:10.1007/s10584-010-9980-9.

Costanza, R., R. d'Arge, R. de Groot, S. Farberk, M. Grasso, B. Hannon, K. Limburg, S. Naeem, R. V. O’Neill, J. Paruelo, R. G. Raskin, P. Suttonkk, and M. van den Belt. 1997. The Value of the World's Ecosystem Services and Natural Capital. Nature 387 (6630): 25360.

Curriero, F. C., K. S. Heiner, J. M. Samet, S. L. Zeger, L. Strug, and J. A. Patz. 2002. Temperature and Mortality in 11 Cities of the Eastern United States. American Journal of Epidemiology 155 (1): 80-87.

D'Ippoliti, D., P. Michelozzi, C. Marino, F. de'Donato, B. Menne, K. Katsouyanni, U. Kirchmayer, A. Analitis, M. Medina-Ramón, A. Paldy, R. Atkinson, S. Kovats, L. Bisanti, A. Schneider, A. Lefranc, C. Iñiguez, and C. A. Perucci. 2010. The Impact of Heat Waves on Mortality in 9 European Cities: Results from the EuroHEAT Project. Environmental Health 9 (1): 37.

DG ECFIN (European Commission Directorate-General for Economic and Financial Affairs). 2006. The Impact of Ageing on Public Expenditure: Projections for the EU25 Member States on Pensions, Health Care, Long-Term Care, Education and Unemployment Transfers (2004-2050). European Economy. Special Report 1. Luxembourg. http://ec.europa.eu/economy_finance/publications/publication6654_ en.pdf.

Dhainaut, J. F., Y. E. Claessens, C. Ginsburg, and B. Riou. 2004. Unprecedented Heat-Related Deaths during the 2003 Heat Wave in Paris: Consequences on Emergency Departments. Critical Care 8 (1): 1-2.

Fink, A. H., T. Brücher, A. Krüger, G. C. Leckebusch, J. G. Pinto, and U. Ulbrich. 2004. The 2003 European Summer Heatwaves and Drought — Synoptic Diagnosis and Impacts. Weather 59 (8): 209-16.

Fouillet, A., G. Rey, V. Wagner, K. Laaidi, P. Empereur-Bissonnet, A. Le Tertre, P. Frayssinet, P. Bessemoulin, F. Laurent, P. De Crouy-Chanel, E. Jougla, and D. Hémon. 2008. Has the Impact of Heat Waves on Mortality Changed in France since the European Heat Wave of Summer 2003? International Journal of Epidemiology 37 (2): 309-17.

Frich, A., L. V. Alexander, P. Della-Marta, B. Gleason, M. Haylock, A. M. G. Klein Tank, and T. Peterson. 2002. Observed Coherent Changes in Climatic Extremes During the Second Half of the Twentieth Century. Climate Research 19 (3): 193-212. DOI:10.3354/ cr019193.

GCP (Global Carbon Project). 2010. Global Carbon Budget 2009. http:// www.globalcarbonproject.org/carbonbudget/09/files/GCP2010_ CarbonBudget2009.pdf.

Hajat, S., S. C. Sheridan, M. J. Allen, M. Pascal, K. Laaidi, A. Yagouti, U. Bickis, A. Tobias, D. Bourque, B. G. Armstrong, and T. Kosatsky. 2010. Heat-Health Warning Systems: A Comparison of the Predictive Capacity of Different Approaches to Identifying Dangerously Hot
Days. American Journal of Public Health 100 (6): 1137-44. DOI:10.2105/AJPH.2009.169748.

Hallegatte, S., and J. Corfee-Morlot. 2011. Understanding Climate Change Impacts, Vulnerability and Adaptation at City Scale: An Introduction. Climatic Change 104 (1), Special Issue: Understanding Climate Change Impacts, Vulnerability and Adaptation at City Scale: 1-12. DOI:10.1007/s10584-010-9981-8.

Hallegatte, S., J.-C. Hourcade, and P. Ambrosi. 2007. Using Climate Analogues for Assessing Climate Change Economic Impacts in Urban Areas. Climatic Change 82 (1-2): 47-60. DOI:10.1007/ s10584-006-9161-z.

Hansen, J., R. Ruedy, M. Sato, and K. Lo. 2010. Global Surface Temperature Change. Reviews of Geophysics 48, RG4004. DOI: 10.1029/2010RG000345.

Hinkel, J., S. Bisaro, T. Downing, M. E. Hoffmann, K. Lonsdale, D. Mcevoy, and J. D. Tabara. 2009. Learning to Adapt. Narratives of Decision Makers Adapting to Climate Change. In Making Climate Change Work for Us: European Perspectives on Adaptation and Mitigation Strategies, edited by M. Hulme, and H. Neufeldt, 113-34. Cambridge: Cambridge University Press.

Hübler, M., G. Klepper, and S. Peterson. 2007. Costs of Climate Change-The Effects of Rising Temperatures on Health and Productivity in Germany. Kiel Working Paper No. 1321. Kiel: Kiel Institute for the World Economy.

IPCC (Intergovernmental Panel on Climate Change). 2007. Climate Change 2007: The Physical Science Basis. Contribution of Working Group I to the Fourth Assessment Report of the Intergovernmental Panel on Climate Change. Edited by Solomon, S., D. Qin, M. Manning, Z. Chen, M. Marquis, K. B. Averyt, M. Tignor, and H. L. Miller. Cambridge: Cambridge University Press.

IRGC (International Risk Governance Council). 2005. IRGC White Paper No 1. Risk Governance - Towards an Integrative Approach. Geneva: IRGC.

IRGC (International Risk Governance Council). 2008. An Introduction to the IRGC Risk Governance Framework. Geneva: IRGC.

Jaeger, C. C., O. Renn, E. A. Rosa, and Th. Webler. 2001. Risk, Uncertainty, and Rational Action. London: Earthscan.

Jaeger, C. C., J. Krause, A. Haas, R. Klein, and K. Hasselmann. 2008. A Method for Computing the Fraction of Attributable Risk Related to Climate Damages With an Application to the Alpine Heat Wave. 2003. Risk Analysis 28 (4): 815-23. DOI:10.1111/j.1539-6924.2008. 01070.x.

Kalkstein, L. S., S. C. Sheridan, and A. J. Kalkstein. 2009. Heat/Health Warning Systems: Development, Implementation, and Intervention Activities. In Biometeorology for Adaptation to Climate Variability and Change, edited by K. L. Ebi, I. Burton, and G. R. McGregor, 33-48. Berlin: Springer. DOI:10.1007/978-1-4020-8921-3 3.

Koppe, C. 2005. Health-Related Assessment of Thermal Stress, Taking into Account Short-Term Adaptation to Local Weather Conditions (Gesundheitsrelevante Bewertung von thermischer Belastung unter Berücksichtigung der kurzfristigen Anpassung der Bevölkerung an die lokalen Witterungsverhältnisse). Ph.D. Dissertation, University of Freiburg, Germany.

Koppe, C., S. Kovats, G. Jendritzky, B. Menne, et al. 2004. Heat-Waves: Risks and Responses. Copenhagen: WHO (World Health Organization). Regional Office for Europe. Health and Global Environmental Change, Series, No. 2.

Kosatsky, T., and B. Menne. 2005. Preparedness for Extreme Weather among National Ministries of Health of WHO's European Region. In Climate Change and Adaptation Strategies for Human Health, edited by B. Menne, and K. L. Ebi, 297-329. Darmstadt: Springer.

Kovats, R. S., and K. L. Ebi. 2006. Heatwaves and Public Health in Europe. European Journal of Public Health 16 (6): 592-99. DOI: 10.1093/eurpub/ck1049.

Kovats, R. S., and G. Jendritzky. 2006. Heat-Waves and Human Health. In Climate Change and Adaptation Strategies for Human Health, edited by B. Menne, and K. L. Ebi, 63-97. Darmstadt: Steinkopff. 
Kovats, R. S, and S. Hajat. 2008. Heat Stress and Public Health: A Critical Review. Annual Review of Public Health 29: 41-55. DOI:10.1146/annurev.publhealth.29.020907.090843.

Lissner, T., A. Holsten, C. Walther, and J. P. Kropp. 2011. Towards Sectoral and Standardised Vulnerability Assessments: The Example of Heatwave Impacts on Human Health. Climatic Change [in press].

Liukaityte, J., and C. Koppe. 2009. Heat-Health Warning Systems in Europe. http://www.isse.ucar.edu/climatehealth/2009/presentations/ Liukaityte_HHWS.pdf.

Matthies, F., and B. Menne. 2009. Prevention and Management of Health Hazards Related to Heatwaves. International Journal of Circumpolar Health 68 (1): 8-22.

McGeehin, M. A., and M. Mirabelli. 2001. The Potential Impacts of Climate Variability and Change on Temperature-Related Morbidity and Mortality in the United States. Environmental Health Perspectives 109 (suppl. 2): 185-89.

McGregor, G., K. Ebi, P. Bessemoulin, and B. Menne. 2010. Heat Waves and Health: Guidance on Warning System Development. For Publication by the World Meteorological Organization and the World Health Organization. Draft Version. http://www.wmo.int/pages/prog/wcp/ ccl/opags/documents/HeatWavesandHealthGuidance_26July2010. pdf.

McMichael, A. J., R. E. Woodruff, and S. Hales. 2006. Climate Change and Human Health: Present and Future Risks. Lancet 367 (9513): 859-69. DOI:10.1016/S0140-6736(06)68079-3.

Meehl, G., and C. Tebaldi. 2004. More Intense, More Frequent, and Longer Lasting Heat Waves in the $21^{\text {st }}$ Century. Science 305 (5686): 994-97.

Michelozzi, P., F. de'Donato, L. Bisanti, A. Russo, E. Cadum, M. DeMaria, M. D'Ovidio, G. Costa, and C. A. Perucci. 2005. The Impact of the Summer 2003 Heatwaves on Mortality in Four Italian Cities. Euro Surveillance 10 (7-9): 161-64.

Millennium Ecosystem Assessment. 2005. Ecosystems and Human Well-Being: Synthesis Report. Washington DC: Island Press.

NHS (National Health Service). 2006. Heatwave Plan for England. Protecting Health and Reducing Harm from Extreme Heat and Heatwaves. Department of Health, UK.

Nogueira, P. J. 2005. Examples of Heat Warning Systems: Lisbon's ICARO's Surveillance System, Summer 2003. In Extreme Weather Events and Public Health Responses, edited by W. Kirch, B. Menne, and R. Bertollini, 141-60. Heidelberg: Springer.

Nye, J. S., and J. Donahue, eds. 2000. Governance in a Globalising World. Brookings Institution, Washington.

Patz, J. A., D. Campbell-Lendrum, T. Holloway, and J. A. Foley. 2005. Impact of Regional Climate Change on Human Health. Nature 438 (7066): 310-17.

Renn, O. 2008. Risk Governance: Coping with Uncertainty in a Complex World. London: Earthscan.

Reusswig, F. 2010. The New Climate Change Discourse: A Challenge for Environmental Sociology. In Environmental Sociology: European Perspectives and Interdisciplinary Challenges, edited by M. Gross, and H. Heinrichs, 34-61. Dordrecht: Springer.

Reusswig, F., and W. Lass. 2010. Post-Carbon Ambivalences. The New Climate Change Discourse and the Risks of Climate Science. In Ambiguous Progress, edited by S. Böschen, and P. Wehling. Science, Technology \& Innovation Studies 6 (2): 155-81.

Robine, J., S. Cheung, S. Le Roy, H. Van Oyen, C. Griffiths, J. Michel, and F. Herrmann. 2008. Death Toll Exceeded 70,000 in Europe during the Summer of 2003. Comptes Rendus Biologies 331 (2): 171-78.
Robinson, P. J. 2001. On the Definition of Heat Waves. Journal of Applied Meteorology 40 (4): 762-75. DOI:10.1175/1520-0450(2001) 040<0762:OTDOAH $>2.0 . \mathrm{CO} ; 2$.

Rosenau, J. N. 1992. Governance, Order, and Change in World Politics. In Governance without Government. Order and Change in World Politics, edited by J. N. Rosenau, and E. O. Czempiel, 1-29. Cambridge: Cambridge University Press.

Schär, C., P. L. Vidale, D. Luthi, C. Frei, C. Haberli, M. A. Liniger, and C. Appenzeller. 2004. The Role of Increasing Temperature Variability in European Summer Heatwaves. Nature 427 (6972): 332-36. DOI: 10.1038/nature02300.

Schifano, P., G. Cappai, M. De Sario, P. Michelozzi, C. Marino, A. M. Bargagli, and C. A Perucci. 2009. Susceptibility to Heat WaveRelated Mortality: A Follow-up Study of a Cohort of Elderly in Rome. Environmental Health 8 (11): 50-64.

Schönwiese, C.-D. 2007. Will the Climate become more Extreme? A Statistical Analysis (Wird das Klima extremer? Eine statistische Analyse). In Climate Change - Insights, Reviews, and Prospects (Der Klimawandel-Einblicke, Rückblicke und Ausblicke), edited by W. Endlicher, and F.-W. Gerstengarbe. Potsdam, Germany.

Seppälä, O., and J. Jokela. 2011. Immune Defence under Extreme Ambient Temperature. Biology Letters 7 (1): 119-22. DOI:10.1098/ rsbl.2010.0459.

Shi, P. J., N. Li, Q. Ye, W. J. Dong, G. Y. Han, and W. H. Fang. 2010. Research on Integrated Disaster Risk Governance in the Context of Global Environmental Change. International Journal of Disaster Risk Science 1 (1): 17-23.

Shuster, S. 2010. Will Russia's Heat Wave End Its Global-Warming Doubts? Time Magazine online, August 2. http://www.time.com/ time/world/article/0,8599,2008081,00.html\#ixzz1NNHxChxk.

Siliverstovs, B., R. Ötsch, C. Kemfert, C. C. Jaeger, A. Haas, and H. Kremers. 2009. Climate Change and Modelling of Extreme Temperatures in Switzerland. Stochastic Environmental Research and Risk Assessment 24 (2): 311-26.

Simón, F., G. López-Abente, E. Ballester, and F. Martínez. 2005. Mortality in Spain during the Heatwaves of Summer 2003. Euro Surveillance 10 (7): 156-60

Souch, C., and S. Grimmond. 2006. Applied Climatology: Urban Climate. Progress in Physical Geography 30 (2): 270-79.

Stern, N., ed. 2006. The Economics of Climate Change: The Stern Review. Cambridge: Cambridge University Press.

Stöckli, R., R. Simmon, and D. Herring. 2011. Land Surface Temperature Difference. http://earthobservatory.nasa.gov/IOTD/view.php?id= 3714.

Stott, P. A., D. A. Stone, and M. R. Allen. 2004. Human Contribution to the European Heatwave of 2003. Nature 432 (7017): 610-14. DOI: 10.1038 /nature 03089 .

Swiss Re. 2011. Natural Catastrophes and Man-Made Disasters in 2010: A Year of Devastating and Costly Events. Sigma 1/2011. Zurich: Swiss Re.

U.S. EPA (U.S. Environmental Protection Agency). 2006. Excessive Heat Events Guidebook. Washington, DC: U.S. Environmental Protection Agency.

WHO Europe (World Health Organization Europe). 2008a. Heat-Health Action Plans. Guidance. Edited by F. Mathies, G. Bickler, N. Cardeñosa Marín, and S. Hales. Copenhagen: WHO Europe.

-. 2008b. Improving Public Health Responses to Extreme Weather / Heat-Waves - EuroHEAT Meeting Report. Bonn, Germany, 22-23 March 2007.

Open Access This article is distributed under the terms of the Creative Commons Attribution License which permits any use, distribution, and reproduction in any medium, provided the original author(s) and source are credited. 